\title{
Association of inflammation with specific symptoms of depression in a general population of older people : The English Longitudinal Study of Ageing
}

\section{White, James}

2017-03

White , J , Kivimaki , M , Jokela , M \& Batty , G D 2017 , ' Association of inflammation with specific symptoms of depression in a general population of older people: The English Longitudinal Study of Ageing ' , Brain, Behavior, and Immunity , vol. 61 , pp. 27-30 . https://doi.org/10.1016/j.bbi.2016

http://hdl.handle.net/10138/235484

https://doi.org/10.1016/j.bbi.2016.08.012

publishedVersion

Downloaded from Helda, University of Helsinki institutional repository.

This is an electronic reprint of the original article.

This reprint may differ from the original in pagination and typographic detail.

Please cite the original version. 
Short Communication

\title{
Association of inflammation with specific symptoms of depression in a general population of older people: The English Longitudinal Study of Ageing
}

\author{
James White PhD ${ }^{\mathrm{a}, \mathrm{b}, *}$, Mika Kivimäki PhD ${ }^{\mathrm{c}, \mathrm{d}}$, Markus Jokela $\mathrm{PhD}^{\mathrm{e}}$, G. David Batty DSc ${ }^{\mathrm{c}}$ \\ ${ }^{a}$ Centre for Trials Research, Cardiff University, Cardiff CF14 4YS, UK \\ ${ }^{\mathrm{b}}$ Centre for the Development and Evaluation of Complex Interventions for Public Health Improvement (DECIPHer), Cardiff University, Cardiff CF14 4YS, UK \\ ${ }^{\mathrm{C}}$ Department of Epidemiology and Public Health, University College London, London, WC1E 7HB, UK \\ ${ }^{\mathrm{d}}$ Clinicum, Faculty of Medicine, University of Helsinki, Helsinki, Finland \\ ${ }^{\mathrm{e}}$ Institute of Behavioural Sciences, University of Helsinki, Helsinki, Finland
}

\section{A R T I C L E I N F O}

\section{Article history:}

Received 24 March 2016

Received in revised form 4 July 2016

Accepted 21 August 2016

Available online 22 August 2016

\section{Keywords:}

C-reactive protein

Depression

Antidepressants

\begin{abstract}
A B S T R A C T
Elevated levels of inflammatory markers, such as C-reactive protein, are well documented in people with depression. Few studies have examined whether the association between inflammation and depression is symptom specific, and differs according to antidepressant treatment. Using data from the English Longitudinal Study of Ageing $(N=5909)$, cross-sectional analyses revealed a significant dose-response association between $C$-reactive protein and the symptoms of fatigue $(P<0.001)$, restless sleep $(P=0.03)$, low energy $(P=0.02)$ and feeling depressed $(P=0.04)$, but not other symptoms. These associations were absent in users of anti-depressant medication. Our findings suggest the C-reactive proteindepression association is symptom-specific and modified by antidepressant treatment.
\end{abstract}

(c) 2016 Elsevier Inc. All rights reserved.

\section{Introduction}

Levels of inflammatory markers, such as C-reactive protein (CRP), are elevated in people with symptoms of depression, although this is not a universal observation (Valkanova et al., 2013). In these studies, depression symptomology is commonly measured with an aggregate score of different symptoms which may mask symptom-specific effects (Valkanova et al., 2013).

Initial analyses into specific symptoms of depression found a significant association between CRP levels with an increased risk that participants reported they had "not accomplished much recently" and felt "like giving up", but not "often feeling nervous or stressed" (Wium-Andersen et al., 2013). These analyses were not, however, mutually adjusted for other symptoms, so they could be attributed to either somatic (e.g., fatigue) or psychological symptoms (e.g., feelings of low self-worth). In a recent item-level analysis of the US National Health and Nutrition Examination Survey, investigators adjusted these associations for the effect of other depressive symptoms and found CRP was independently associ-

\footnotetext{
* Corresponding author at: Centre for the Development and Evaluation of Complex Interventions for Public Health Improvement (DECIPHer), Cardiff University, Cardiff CF14 4YS, UK.

E-mail addresses: whitej11@cf.ac.uk (J. White), m.kivimaki@ucl.ac.uk (M. Kivimäki), markus.jokela@helsinki.fi (M. Jokela), david.batty@ucl.ac.uk (G.D. Batty).
}

ated with somatic (e.g., reports of tiredness, lack of energy, sleep problems and lack of appetite) but not psychological symptoms of depression (e.g., reports of depressed mood, anhedonia, feelings of self-worth) (Jokela et al., 2016).

We examined these relationships in the English Longitudinal Study of Ageing (ELSA), a population of older people in whom levels of inflammatory markers and the occurrence of depression tend to be higher. Additionally, given that antidepressant drug therapy can have an inflammation-lowering effect (Hannestad et al., 2011), we explore the link between inflammation and specific symptoms of depression according to the use of such medication.

\section{Materials and methods}

\subsection{Participants}

Initiated in 2002/03 when study members were 50 years of age or older, the ELSA is an on-going, biennial, nationally representative, multi-disciplinary prospective cohort study of older people (Steptoe et al., 2013). Ethical approval was given by the National Research Ethics Service (MREC/01/2/91) and written informed consent obtained from all participants. 
For the present analyses, we report on data collected at wave six (2012-2013), when blood samples for CRP and medication use were collected by nurses (Steptoe et al., 2013). A total of 10,601 participants attended the wave six assessment, with 4476 excluded from our analysis owing to missing data on CRP, or incomplete data on depressive symptoms, medication use, or potential confounding or mediating factors $(n=216)$, resulting in a final sample size of 5909 (mean age, 66 years; $54.9 \%$ female). Missing values on CRP were due to exclusions placed on participants who had a clotting or bleeding disorder (e.g., haemophilia or low platelets), those who had ever had a fit or convulsion in the last five years, were currently taking anticoagulant drugs (e.g., warfarin), or were unwilling to give their consent in writing for the drawing of blood (Steptoe et al., 2013).

\subsection{C-reactive protein}

CRP was measured using standard procedures (median, $1.6 \mathrm{mg} /$ $\mathrm{L}$; interquartile range, $0.8-3.2 \mathrm{mg} / \mathrm{L}$ ) (Bridges et al., 2012) and analysed using the $\mathrm{N}$ Latex CRP mono Immunoassay on the Behring Nephelometer II Analyzer (Dade Behring, Milton Keynes, UK). As the original (Shapiro-Wilk test: $V=2169.78, P<0.001$ ) and logtransformed $(V=30.79, \quad P<0.001)$ CRP data were originally skewed, we categorized values into quartiles.

\subsection{Depressive symptoms}

Depressive symptoms were assessed using the eight-item version of the Centre for Epidemiological Studies-Depression scale (CES-D) which has comparable psychometric properties to the full 20-item CES-D (Turvey et al., 1999). Items captured information on whether or not participants had experienced different symptoms of depression, "much of the time" in the past week. Items were categorized according to a 3-factor solution (negative affect, anhedonia, somatic) identified in an analysis of CES-D data across five cohort studies (Carleton et al., 2013). We characterised items loading on negative affect and anhedonia factors as assessing psychological symptoms, resulting in three somatic symptoms ("everything I did was an effort", "sleep was restless" and "I could not get going") and five psychological symptoms ("enjoyed life", "felt depressed", “happy", “lonely”, “felt sad”).

\subsection{Confounding variables}

Information on self-reported physician-diagnoses of autoimmune and inflammatory disorders were recorded (diabetes, rheumatoid arthritis, and coronary heart disease). The use of medications with an anti-inflammatory effect (glucocorticoids and beta blockers), antidepressants and body mass index (BMI) were assessed during a visit to participants' homes by nurses. Antidepressants, glucocorticoids and beta blockers were categorized using the British National Formulary (BNF) 61 ("British National Formulary (BNF) 61 - March 2011").

\subsection{Statistical analysis}

We used $\chi^{2}$ test to examine differences in categorical variables. Depressive symptoms were treated as dichotomous variables (no $=0$, yes $=1$ ). We examined associations between quartiles of CRP and individual CES-D items in separate logistic regression models in which effect estimates were adjusted for sex, age, and race/ethnicity, and the sum of the remaining items (to account for the overlap between different depressive symptoms), autoimmune and inflammatory disorders, glucocorticoids and beta blockers (model 1). We then additionally adjusted for BMI (model 2). We tested for a difference in the trend across quartiles of CRP using orthogonal polynomial contrasts. We then included an interaction term between quartiles of CRP and antidepressant treatment.

A sensitivity analysis using linear regression examined the association between CRP with the sum of the three items assessing somatic symptoms, and also the sum of the five psychological symptoms. All analyses were conducted using Stata 13.

\section{Results}

\subsection{Association between C-reactive protein and depressive symptoms}

After adjusting for autoimmune disorders, inflammatory disorders, and anti-inflammatory medication there was an independent, dose-response association between quartiles of CRP and somatic symptoms relating to everything being an effort (odds ratios [ORs] of $1.20,1.31$, and 1.97 for the second, third, and fourth quartiles of CRP respectively, compared with the first; $P$ for trend $<0.001$ ), restless sleep (ORs of $1.11,1.15$, and 1.37; $P$ for trend $=0.002$ ), and not being able to get going (ORs of 1.33, 1.40, and $1.60 ; P$ for trend $=0.007$ ). The association with negative affect ("felt depressed") was also statistically significant $(P$ for trend $=0.03$ ); but for other items relating to affect (sadness) and anhedonia were not (Tables 1 and 2). Additional adjustment for BMI partially attenuated estimates for restless sleep (ORs of 1.08, 1.11 , and $1.30 ; P$ for trend $=0.002$ ) and not being able to get going (ORs of 1.28, 1.31, and 1.45; $P$ for trend $=0.02$ ).

\subsection{Association between C-reactive protein and depressive symptoms stratified by antidepressant use}

For the one in ten participants who took antidepressants (10.6\%), the association between CRP and all but the symptoms of restless sleep (model 1: $P=0.03$; model 2: $P=0.04$ ) and feeling depressed $(P=0.02)$ were not significant at conventional levels (model 1: Tables S1 and S2). In contrast, among study members not treated with antidepressants, there was an independent dose-response association for somatic symptoms (Table S3). The associations between CRP and restless sleep $(P=0.16)$ and not being able to get going $(P=0.12)$ were attenuated after adjustment for BMI, whereas the association for everything being an effort was not $(P<0.001)$.

There was a non-significant association between quartiles of CRP and psychological symptoms among those untreated with antidepressants (Table S3), and an inverse association between CRP and feeling depressed $(P=0.02)$. A significant interaction indicated the dose-response trend was stronger in those untreated than treated with antidepressants for the items relating to fatigue/low motivation - everything being an effort $(P$ for a difference in trend $=0.02$ ) and restless sleep ( $P$ for a difference in trend $=0.04$, see Supplementary Fig. 1).

\subsection{Sensitivity analyses}

People with missing data had fewer symptoms of depression $(P<0.001)$, except restless sleep $(P=0.09)$; fewer reported baseline heart disease $(P=0.005)$, diabetes, rheumatoid arthritis and used antidepressants $(P<0.001)$; they had a lower body mass index and level of CRP $(P<0.001)$, more took beta blockers $(P=0.03)$, but no differences were found by age, sex, or the use of glucocorticoids $(P>0.05)$. The pattern of attenuation for our main results was replicated in models using the sum of the items assessing somatic (Tables S5) or psychological symptoms (Tables S6). 
Table 1

Association between quartiles of C-reactive protein and 'somatic' depression symptoms in the ELSA cohort $(\mathrm{N}=5909)$.

\begin{tabular}{|c|c|c|c|c|}
\hline \multirow[t]{2}{*}{ Outcome } & \multirow[t]{2}{*}{ C-reactive protein (mg/L) } & \multirow[t]{2}{*}{ Symptomatic, \% (N) } & \multicolumn{2}{|l|}{ OR $(95 \% \mathrm{CI})^{\mathrm{ab}}$} \\
\hline & & & Model 1 & Model 2 \\
\hline \multirow[t]{4}{*}{ Everything they did was an effort } & $0.10-0.79$ & $11.6(190)$ & 1.00 (reference) & 1.00 (reference) \\
\hline & $0.80-1.60$ & $14.9(215)$ & $1.20(0.95,1.52)$ & $1.20(0.94,1.53)$ \\
\hline & $1.61-3.30$ & $16.2(230)$ & $1.31(1.03,1.65)$ & $1.31(1.03,1.66)$ \\
\hline & $3.31-157.50$ & $24.4(342)$ & $1.97(1.58,2.47)$ & $1.97(1.56,2.50)$ \\
\hline P-trend & & & $<0.001$ & $<0.001$ \\
\hline \multirow[t]{4}{*}{ Sleep was restless } & $0.10-0.79$ & $29.5(485)$ & 1.00 (reference) & 1.00 (reference) \\
\hline & $0.80-1.60$ & $32.6(471)$ & $1.11(0.94,1.30)$ & $1.08(0.91,1.28)$ \\
\hline & $1.61-3.30$ & $33.8(480)$ & $1.15(0.98,1.35)$ & $1.11(0.94,1.31)$ \\
\hline & $3.31-157.50$ & $40.4(566)$ & $1.37(1.16,1.60)$ & $1.30(1.09,1.54)$ \\
\hline P-trend & & & 0.002 & 0.03 \\
\hline \multirow[t]{4}{*}{ Could not get going much of the time } & $0.10-0.79$ & $11.6(190)$ & 1.00 (reference) & 1.00 (reference) \\
\hline & $0.80-1.60$ & $15.6(226)$ & $1.33(1.06,1.68)$ & $1.28(1.01,1.62)$ \\
\hline & $1.61-3.30$ & $16.7(238)$ & $1.40(1.11,1.76)$ & $1.31(1.03,1.66)$ \\
\hline & $3.31-157.50$ & $21.9(307)$ & $1.60(1.27,1.99)$ & $1.45(1.14,1.84)$ \\
\hline P-trend & & & 0.007 & 0.02 \\
\hline
\end{tabular}

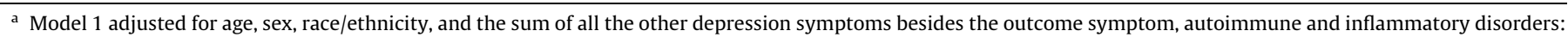

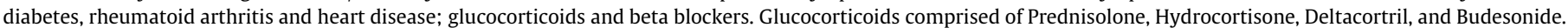
Beta blockers comprised of Atenolol, Bisoprolol, Metoprolol, Propranolol Hydrochloride, and Labetalol Hydrochloride.

b Model 2 comprised model 1 plus body mass index.

Table 2

Association between Quartiles of C-reactive Protein and 'Psychological' Depression Symptoms in the ELSA cohort (N = 5909).

\begin{tabular}{|c|c|c|c|c|}
\hline \multirow[t]{2}{*}{ Outcome } & \multirow[t]{2}{*}{ C-reactive protein $(\mathrm{mg} / \mathrm{L})$} & \multirow[t]{2}{*}{ Symptomatic, \% (N) } & \multicolumn{2}{|l|}{ OR $(95 \% \mathrm{CI})^{\mathrm{ab}}$} \\
\hline & & & Model 1 & Model 2 \\
\hline Felt depressed much of the time & $\begin{array}{l}0.10-0.79 \\
0.80-1.60 \\
1.61-3.30 \\
3.31-157.50\end{array}$ & $\begin{array}{l}8.4(138) \\
12.0(174) \\
11.8(168) \\
14.1(197)\end{array}$ & $\begin{array}{l}1.00 \text { (reference) } \\
1.45(1.11,1.88) \\
1.37(1.05,1.78) \\
1.24(0.96,1.62)\end{array}$ & $\begin{array}{l}1.00 \text { (reference) } \\
1.44(1.11,1.88) \\
1.36(1.03,1.78) \\
1.23(0.93,1.63)\end{array}$ \\
\hline P-trend & & & 0.03 & 0.04 \\
\hline Happy much of the time & $\begin{array}{l}0.10-0.79 \\
0.80-1.60 \\
1.61-3.30 \\
3.31-157.50\end{array}$ & $\begin{array}{l}91.5(1502) \\
90.5(1309) \\
90.9(1290) \\
89.1(1248)\end{array}$ & $\begin{array}{l}1.00 \text { (reference) } \\
1.02(0.77,1.34) \\
1.07(0.81,1.41) \\
1.16(0.88,1.53)\end{array}$ & $\begin{array}{l}1.00 \text { (reference) } \\
0.98(0.74,1.29) \\
1.00(0.75,1.33) \\
1.05(0.78,1.41)\end{array}$ \\
\hline P-trend & & & 0.72 & 0.96 \\
\hline Lonely much of the time & $\begin{array}{l}0.10-0.79 \\
0.80-1.60 \\
1.61-3.30 \\
3.31-157.50\end{array}$ & $\begin{array}{l}9.1(149) \\
9.3(135) \\
10.2(144) \\
13.6(190)\end{array}$ & $\begin{array}{l}1.00 \text { (reference) } \\
0.89(0.70,1.16) \\
0.92(0.72,1.19) \\
1.05(0.82,1.34)\end{array}$ & $\begin{array}{l}1.00 \text { (reference) } \\
0.89(0.69,1.16) \\
0.94(0.72,1.22) \\
1.07(0.82,1.39)\end{array}$ \\
\hline P-trend & & & 0.56 & 0.53 \\
\hline Enjoyed life much of the time & $\begin{array}{l}0.10-0.79 \\
0.80-1.60 \\
1.61-3.30 \\
3.31-157.50\end{array}$ & $\begin{array}{l}92.8(1524) \\
91.9(1330) \\
90.8(1288) \\
89.8(1258)\end{array}$ & $\begin{array}{l}1.00 \text { (reference) } \\
1.03(0.77,1.39) \\
0.87(0.66,1.16) \\
1.05(0.79,1.41)\end{array}$ & $\begin{array}{l}1.00 \text { (reference) } \\
0.97(0.72,1.31) \\
0.78(0.58,1.05) \\
0.90(0.66,1.22)\end{array}$ \\
\hline P-trend & & & 0.57 & 0.36 \\
\hline Felt sad much of the time & $\begin{array}{l}0.10-0.79 \\
0.80-1.60 \\
1.61-3.30 \\
3.31-157.50\end{array}$ & $\begin{array}{l}15.8(259) \\
17.1(248) \\
16.2(230) \\
19.1(267)\end{array}$ & $\begin{array}{l}1.00 \text { (reference) } \\
0.99(0.81,1.22) \\
0.87(0.70,1.07) \\
0.83(0.67,1.03)\end{array}$ & $\begin{array}{l}1.00 \text { (reference) } \\
1.00(0.81,1.23) \\
0.87(0.70,1.08) \\
0.83(0.66,1.04)\end{array}$ \\
\hline P-trend & & & 0.22 & 0.27 \\
\hline
\end{tabular}

${ }^{a}$ Model 1 adjusted for age, sex, race/ethnicity, and the sum of all the other depression symptoms besides the outcome symptom, autoimmune and inflammatory disorders:

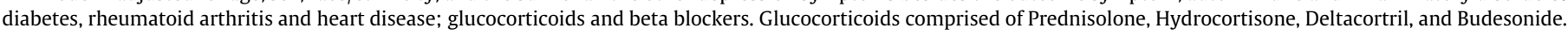
Beta blockers comprised of Atenolol, Bisoprolol, Metoprolol, Propranolol Hydrochloride, and Labetalol Hydrochloride.

b Model 2 comprised model 1 plus body mass index.

\section{Discussion}

We replicated the association between circulating CRP levels and the somatic symptoms of fatigue, restless sleep, and low levels of energy, in a representative community-based cohort of older adults. Importantly, we only found this association to be present in individuals who did not take antidepressants. This suggests that antidepressants modify the association between CRP and the somatic symptoms of depression, in particular symptoms related to fatigue and low motivation.
The graded association between CRP with restless sleep, fatigue and low motivation was partially explained by differences in BMI. This pattern of attenuation replicates that found in previous studies of CRP and the treatment for depression in elderly men (Almeida et al., 2007) and depressive symptoms on the Patient Health Questionnaire in US Army soldiers (Douglas et al., 2004). Our results extend these findings to suggest that the attenuation by BMI may be more relevant for somatic than psychological symptoms. This attenuation could be due to confounding, whereby BMI increases levels of CRP and somatic depressive symptoms. 
However, it is also possible that BMI mediates the influence of CRP on somatic depressive symptoms, or that BMI influences CRP levels which, in turn, induce depressive symptoms. No attenuation was found for the CES-D item on "everything they did was an effort" suggesting that this symptom is linked to CRP independently of the effects of BMI.

Antidepressant use appeared to modify the association between CRP and somatic symptoms. Antidepressants may exert part of their effect through inhibition of inflammatory pathways (Hannestad et al., 2011), which is consistent with a metaanalysis showing inflammation is reduced after antidepressant treatment among people with depression (O'Brien et al., 2006), and two clinical trials showing decreases in interleukin-6 (Abbasi et al., 2012) and CRP (Raison et al., 2013) were associated with the treatment response from antidepressants.

Our study has a number of strengths. It is the first study to examine the association between specific symptoms of depression and CRP according to antidepressant use. That the pattern of results we found closely replicates those from a US-based, younger cohort (US NHANES mean age $=48$ years) (Jokela et al., 2016) and two population-based Danish studies (Wium-Andersen et al., 2013), with different measures of depressive symptoms, supports the generalizability of our findings. The main limitation of this study is loss to follow-up, a perennial problem in longitudinal studies. The eligibility criteria placed on participants to provide a blood sample means those included may have been healthier than the overall cohort. The smaller number of antidepressant users meant we had less power in analyses for users than non-users. In addition, the possibility of survivor bias is a concern with any study of ageing, where fewer unhealthy participants with high levels of CRP are available for analysis, such that the association with depressive symptoms might be underestimated. To influence the pattern of results we found, this bias would, however, have to operate systematically according to antidepressant use.

\section{Acknowledgements}

Author contributions: Dr. White had full access to all data in the study and take responsibility for the integrity of the data and the accuracy of the data analysis.

Study concept and design: Kivimäki, Batty.

Acquisition of data: White, Batty.

Analysis and interpretation of data: All authors.

Critical revision of the manuscript for important intellectual content: All authors.

Statistical analysis: White.

Obtained funding: All authors.

Study supervision: All authors.

Conflict of interest disclosures: All authors declare: no support from any organisation for the submitted work; no financial relationships with any organisations that might have an interest in the submitted work in the previous three years; no other relationships or activities that could appear to have influenced the submitted work.

Funding/support: The preparation of this manuscript was unfunded. Funding for English Longitudinal Study of Ageing is provided by the National Institute of Aging in the United States, and a consortium of UK government departments coordinated by the Office for National Statistics. JW is supported by The Centre for the Development and Evaluation of Complex Interventions for Public Health Improvement, a UKCRC Public Health Research: Centre of Excellence. Funding from the British Heart Foundation, Cancer Research UK, Economic and Social Research Council (ESRC RES-
590-28-0005), Medical Research Council, the Welsh Assembly Government and the Wellcome Trust (WT087640MA), under the auspices of the UK Clinical Research Collaboration, and the contribution is gratefully acknowledged. MK is supported by the UK Medical Research Council, the Academy of Finland, NordForsk, the Nordic Programme on Health and Welfare and by a professorial fellowship from the Economic and Social Research Council.

Role of funding source: Funders had no role in the design and conduct of the study; collection, management, analysis, and interpretation of the data; preparation, review, or approval of the manuscript; and decision to submit the manuscript for publication.

Data sharing: Users registered with the Economic and Social Data Service (ESDS) have access to the English Longitudinal Study of Ageing datasets, available at www.esds.ac.uk.

\section{Appendix A. Supplementary data}

Supplementary data associated with this article can be found, in the online version, at http://dx.doi.org/10.1016/j.bbi.2016.08.012.

\section{References}

Abbasi, S.-H., Hosseini, F., Modabbernia, A., Ashrafi, M., Akhondzadeh, S., 2012. Effect of celecoxib add-on treatment on symptoms and serum IL-6 concentrations in patients with major depressive disorder: randomized double-blind placebo-controlled study. J. Affect. Disord. 141, 308-314. http:// dx.doi.org/10.1016/j.jad.2012.03.033.

Almeida, O.P., Norman, P., Hankey, G.J., Jamrozik, K., Flicker, L., 2007. The association between C-reactive protein concentration and depression in later life is due to poor physical health: results from the Health in Men Study (HIMS). Psychol. Med. 37, 1775-1786. http://dx.doi.org/10.1017/S0033291707000827.

British National Formulary (BNF) 61 - March 2011 [WWW Document], n.d. URL <https://www.tsoshop.co.uk/bookstore.asp?FO=1167771\&DI=629716> (accessed 2.29.16).

Bridges, S., Hussey, D., Blake, M., 2012. Technical Report (ELSA Wave 6) The Dynamics of Ageing: Evidence from the English Longitudinal Study of Ageing 2002-12. NatCen.

Carleton, R.N., Thibodeau, M.A., Teale, M.J.N., Welch, P.G., Abrams, M.P., Robinson, T. Asmundson, G.J.G., 2013. The center for epidemiologic studies depression scale: a review with a theoretical and empirical examination of item content and factor structure. PLoS One 8, e58067. http://dx.doi.org/10.1371/journal. pone.0058067.

Douglas, K.M., Taylor, A.J., O’Malley, P.G., 2004. Relationship between depression and C-reactive protein in a screening population. Psychosom. Med. 66, 679683. http://dx.doi.org/10.1097/01.psy.0000138132.66332.85.

Hannestad, J., DellaGioia, N., Bloch, M., 2011. The effect of antidepressant medication treatment on serum levels of inflammatory cytokines: a metaanalysis. Neuropsychopharmacology 36, 2452-2459. http://dx.doi.org/10.1038/ npp.2011.132.

Jokela, M., Virtanen, M., Batty, G.D., Kivimäki, M., 2016. Inflammation and specific symptoms of depression. JAMA Psychiatry 73, 87-88. http://dx.doi.org/ 10.1001/jamapsychiatry.2015.1977.

O’Brien, S.M., Scott, L.V., Dinan, T.G., 2006. Antidepressant therapy and C-reactive protein levels. Br. J. Psychiatry 188, 449-452. http://dx.doi.org/10.1192/bjp. bp.105.011015.

Raison, C.L., Rutherford, R.E., Woolwine, B.J., Shuo, C., Schettler, P., Drake, D.F., Haroon, E., Miller, A.H., 2013. A randomized controlled trial of the tumor necrosis factor antagonist infliximab for treatment-resistant depression: the role of baseline inflammatory biomarkers. JAMA Psychiatry 70, 31-41. http:// dx.doi.org/10.1001/2013.jamapsychiatry.4.

Steptoe, A., Breeze, E., Banks, J., Nazroo, J., 2013. Cohort profile: The English Longitudinal Study of Ageing. Int. J. Epidemiol. 42, 1640-1648. http://dx.doi. org/10.1093/ije/dys168.

Turvey, C.L., Wallace, R.B., Herzog, R., 1999. A revised CES-D measure of depressive symptoms and a DSM-based measure of major depressive episodes in the elderly. Int. Psychogeriatr. 11, 139-148. http://dx.doi.org/10.1017/ S1041610299005694.

Valkanova, V., Ebmeier, K.P., Allan, C.L., 2013. CRP, IL-6 and depression: a systematic review and meta-analysis of longitudinal studies. J. Affect. Disord. 150, 736744. http://dx.doi.org/10.1016/j.jad.2013.06.004.

Wium-Andersen, M., Ørsted, D., Nielsen, S., Nordestgaard, B., 2013. Elevated Creactive protein levels, psychological distress, and depression in 73,131 individuals. JAMA Psychiatry 70, 176-184. http://dx.doi.org/10.1001/ 2013.jamapsychiatry.102. 